\title{
New species of Isoneuromyia Brunetti (Diptera: Keroplatidae) from the Oriental Region
}

\author{
NEAL L. EVENHUIS
}

J. Linsley Gressitt Center for Research in Entomology, Bishop Museum, 1525 Bernice Street, Honolulu, Hawaii 96817,USA. E-mail: neale@bishopmuseum.org

\section{Table of contents}

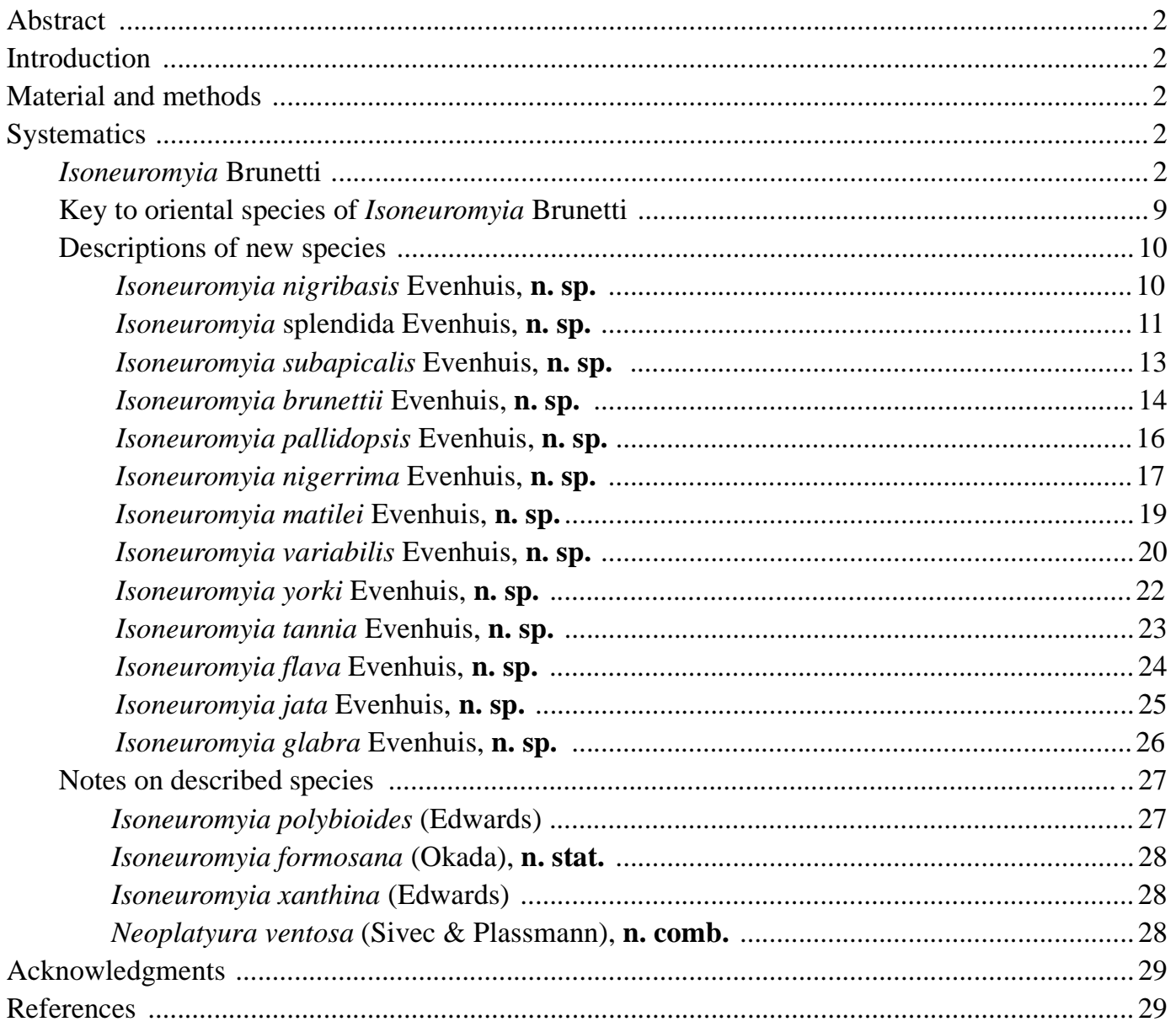


Abstract

Thirteen new species of the keroplatid genus Isoneuromyia Brunetti from the Oriental Region are described and illustrated. These include the following: I. brunettii, n. sp. (Laos); I. flava, n. sp. (Borneo); I. glabra, n. sp. (Laos); I. jata, n. sp. (Borneo); I. matilei, n. sp. (Borneo); I. nigerrima, n. sp. (Laos); I. nigribasis, n. sp. (Laos); I. pallidopsis, n. sp. (Sulawesi); I. splendida, n. sp. (Laos); I. subapicalis, n. sp. (Laos); I. tannia, n. sp. (Borneo); I. variabilis, n. sp. (Laos); I. yorki, n. sp. (Vietnam). The Taiwanese I. annandalei formosana (Okada) is here raised to full species, $\mathbf{n}$. stat. The Sri Lankan species Orfelia (Isoneuromyia) ventosa Sivec \& Plassmann is transferred to Neoplatyura. A key to Oriental species is given.

Key words: Keroplatidae, Isoneuromyia, taxonomy, Borneo, Sulawesi, Laos, Vietnam, Malaysia

\section{Introduction}

Examination of a large amount of undetermined material of Keroplatidae originating from Bishop Museum collecting programs in Indochina, Indonesia, and Borneo over the last forty years has revealed thirteen new species of the genus Isoneuromyia Brunetti that are described here. A key is given to all known Oriental species to aid in their identification. With the description of these new species and the transferal of the Sri Lankan species Orfelia (Isoneuromyia) ventosa Sivec \& Plassmann to Neoplatyura (vide infra), the total number of known Oriental species of Isoneuromyia is now twenty-one. This makes the Oriental Region the most speciose zoogeographical region of the globe for Isoneuromyia (the Neotropical Region has 20). Undoubtedly, more species await discovery here, especially in the Indian Subregion.

\section{Material and methods}

Material in this study derives from specimens in the Bishop Museum (BPBM). Holotypes of all new species in this study are deposited in BPBM. Paratypes are also deposited there, with duplicate paratypes, when numbers of specimens permit, deposited in the Museum National d'Histoire Naturelle, Paris (MNHN).

Morphological terminology follows that of Soli et al. (2000).

\section{Systematics}

\section{Isoneuromyia Brunetti}

Isoneuromyia Brunetti, 1912: 66. Type species: Isoneuromyia annandalei Brunetti, 1912, by subsequent designation (Edwards, 1925: 166). 
Isoneuromyia is a keroplatid genus of over 50 species found primarily in the Oriental and Neotropical Regions, with a few species also found in the Palaearctic, Nearctic, and Australasian/Oceanian Regions. They vary in size but can range from some of the largest keroplatids known (over $18 \mathrm{~mm}$ in length) to smaller species less than $5 \mathrm{~mm}$ in length. All have strong brown wing veins and elongate abdomens. Some are wasp mimics, where species have the terminal abdominal segments expanded and flattened (cf. Figs. 27-28). Nothing is known of their larval habitats.

Brunetti (1912: 66) described Isoneuromyia based on two included species: I. annandalei and $I$. rufescens but did not designate a type species. Most authors subsequently treated the type fixation as I. annandalei by monotypy, having missed the fact that $I$. rufescens was described in the same work, but in the Appendix on p. 559. E dwards (1925: 166) was the first to make a formal subsequent designation of I. annandalei as the type species.

Brunetti (1912) distinguished Isoneuromyia from Platyura and other Indian keroplatids by the strong wing venation. However, this character is also found in species in other genera of Keroplatidae, and thus by itself cannot be used to distinguish the genus. The following characters used to distinguish Isoneuromyia in keys by Hutson et al. (1980), Chandler \& Ribeiro (1995), Soli et al. (2000), and Vockeroth (in press) include laterotergite, mediotergite, and anepimeron bare; tibiae with spines in regular rows throughout; costal vein not extending past $\mathrm{R}_{5}$; vein $\mathrm{A}_{1}$ almost reaching wing margin; and bases of forked veins with minute spines (sometimes only seen under high magnification). Matile (1990) treated the shape of the male genitalia as a "primitive" condition, consisting of macrocerine-looking gonostyli with normally bidentate apices (cf. Figs. 34-43).

Additional characters that may be useful in distinguishing Isoneuromyia from other genera and in distinguishing species within the genus have been found in the species from the Oriental Region in this study and are briefly annotated below.

\section{Head}

Facial shape: The face is produced to varying degrees and slightly hook shaped in lateral view (Figs. 1-2), which is reminiscent of Platyura facial characteristics. Species of Truplaya Edwards also have this character state but can be distinguished from Isoneuromyia by the tibial spines being irregularly arranged basally (in regular rows along entire length of tibia in Isoneuromyia).

Palpi: The palpi have similar shapes all through the genus but coloration can differ among species (from all brown to all yellow).

Antennae: The antennal segmental shapes are fairly consistent throughout the species examined. The only variation found is in coloration. In the Oriental species, the color of the apical flagellomeres can be of significance. Some species have the flagellomeres unicolorous, while others have bicolored antennae (i.e., the basal flagellomeres are a contrasting color to the apical flagellomeres) (cf. Figs. 3-6). 

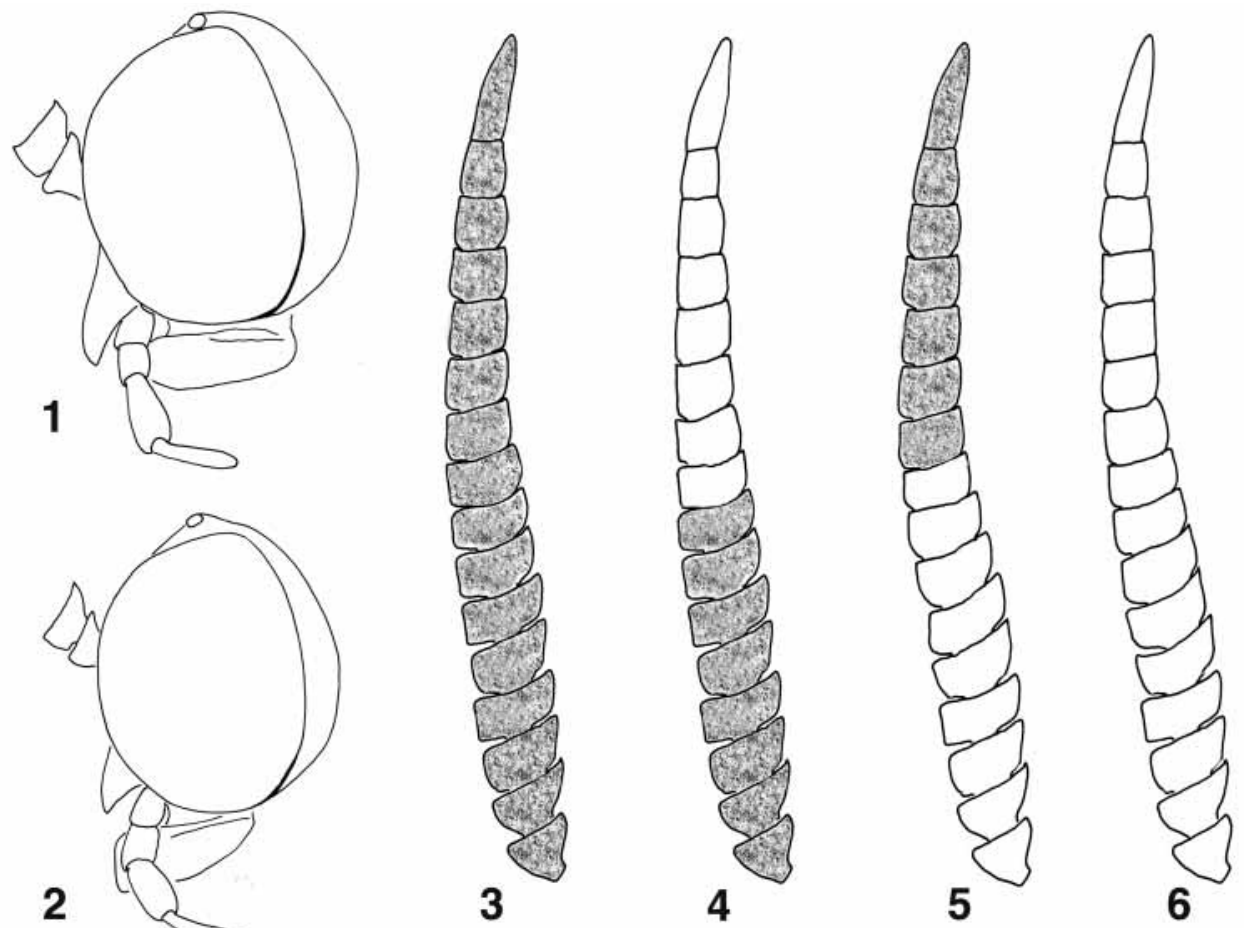

FIGURES 1-6. 1-2. Isoneuromyia heads, lateral view, showing general shapes, antennal flagellomeres and vestiture removed. 1. I. splendida, n. sp. 2. I. yorki, n. sp. 3-6. Isoneuromyia antennae, lateral view. 3. I. nigerrima, n. sp. 4. I. splendida, n. sp. 5. I. polybioides (Edwards). 6. I. glabra, n. sp.

Thorax

Prescutellar shape: Two types have been found in the specimens examined from the Oriental Region: 1) a normal type tapering from the postalar calli to the scutellum and with the scutellum relatively normal in shape and size (Fig. 11); and 2) a flared condition in which the prescutellum has developed into a shield-like structure slightly covering a very minute scutellum (Fig. 13).

Mesonotal pattern: Most species examined in this study from the Oriental Region have a pattern of two admedian stripes and a central median stripe. These may be coalesced into one (Fig. 13); all separate (Fig. 15); or with the median stripe faded, reduced, or absent altogether (Fig. 12). Other species have a unicolorous mesonotum (cf. Fig. 18). These differences may not be of phylogenetic significance but can be useful in distinguishing species.

Legs

Tibial spurs: Tibial spur color is predominantly brown to black; however, there is a group of species from Borneo and Sulawesi that have orange to yellow tibial spurs. Further study is needed to determine if this character state is of phylogenetic significance. 

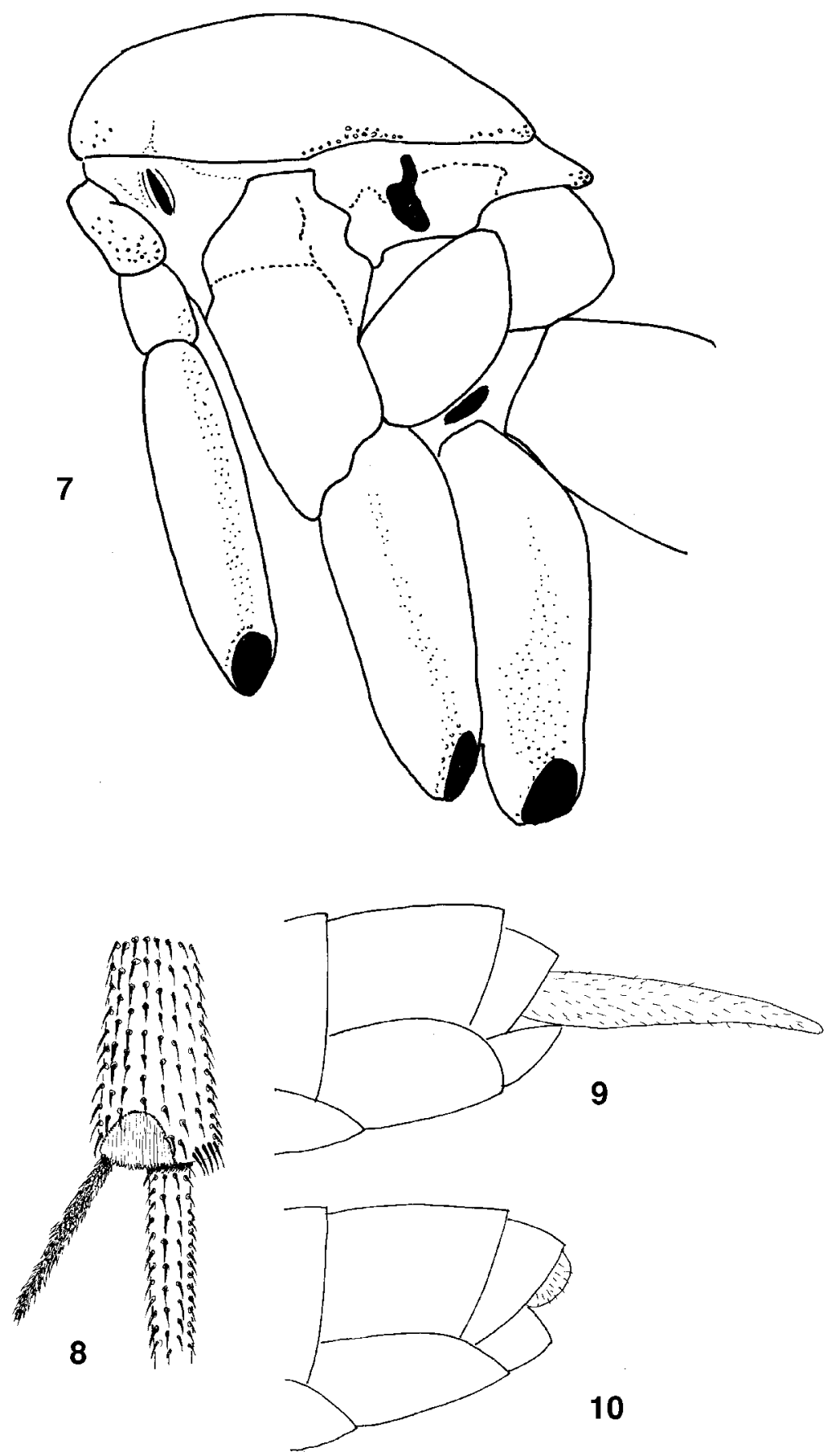

FIGURES 7-10. 7. Isoneuromyia splendida, n. sp., thorax, lateral view, vestiture removed. 8. Isoneuromyia variabilis, n. sp., apex of fore tibia showing tibial pecten in association with tibial spur. 9-10. Isoneuromyia female terminal abdominal segments, showing relative lengths of cerci. 9. I brunettii, n. sp. 10. I. yorki, n. sp. 

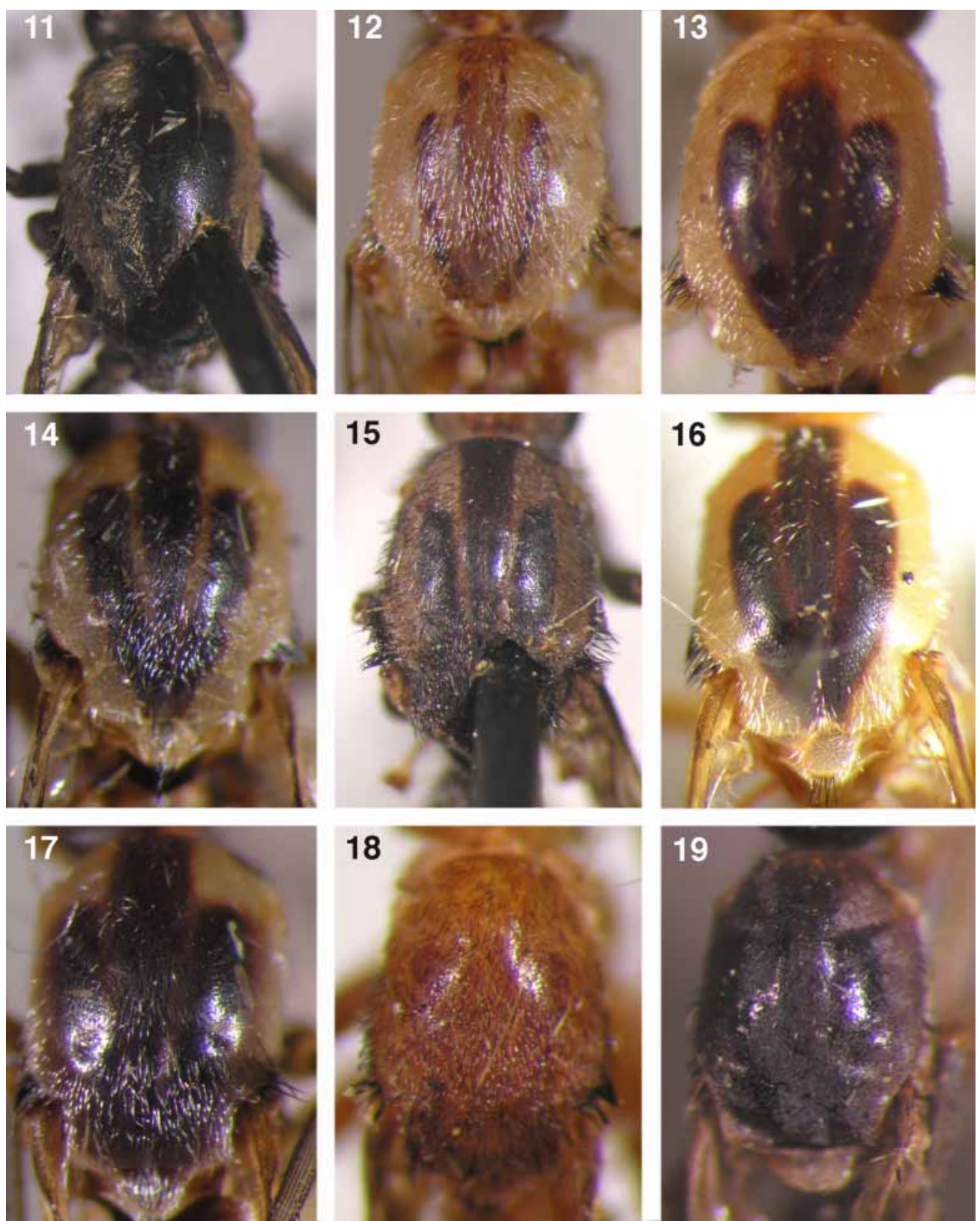

FIGURES 11-19. Isoneuromyia thoraces, dorsal view. 11. I. brunettii, n. sp. 12. I. flava, n. sp. 13. I. glabra, n. sp. 14. I. matilei, n. sp. 15. I. nigribasis, n. sp. 16. I. pallidopsis, n. sp. 17. I. splendida, n. sp. 18. I. xanthina (Edwards). 19. I. yorki, n. sp.

\section{Wing}

Venation: All veins are strong and brown to dark brown in color. Brunetti (1912) did not indicate if the veins all reached the wing margin, but his illustrations of grandis and annandale $i$ seem to indicate that at least veins $\mathrm{M}_{2}$ and $\mathrm{A}_{1}$ do not reach the wing margin. In 
all of the specimens examined in this study, vein $\mathrm{M}_{2}$ did not reach the wing margin. Most had veins $\mathrm{M}_{2}$ and $\mathrm{CuA}_{1}$ not reaching the wing margin. Some additionally had $\mathrm{CuA}_{2}$ and $\mathrm{A}_{1}$ not reaching the margin. Vein $\mathrm{M}_{1}$ almost always reaches the margin but has the sclerotization much weakened at the apex of the vein.
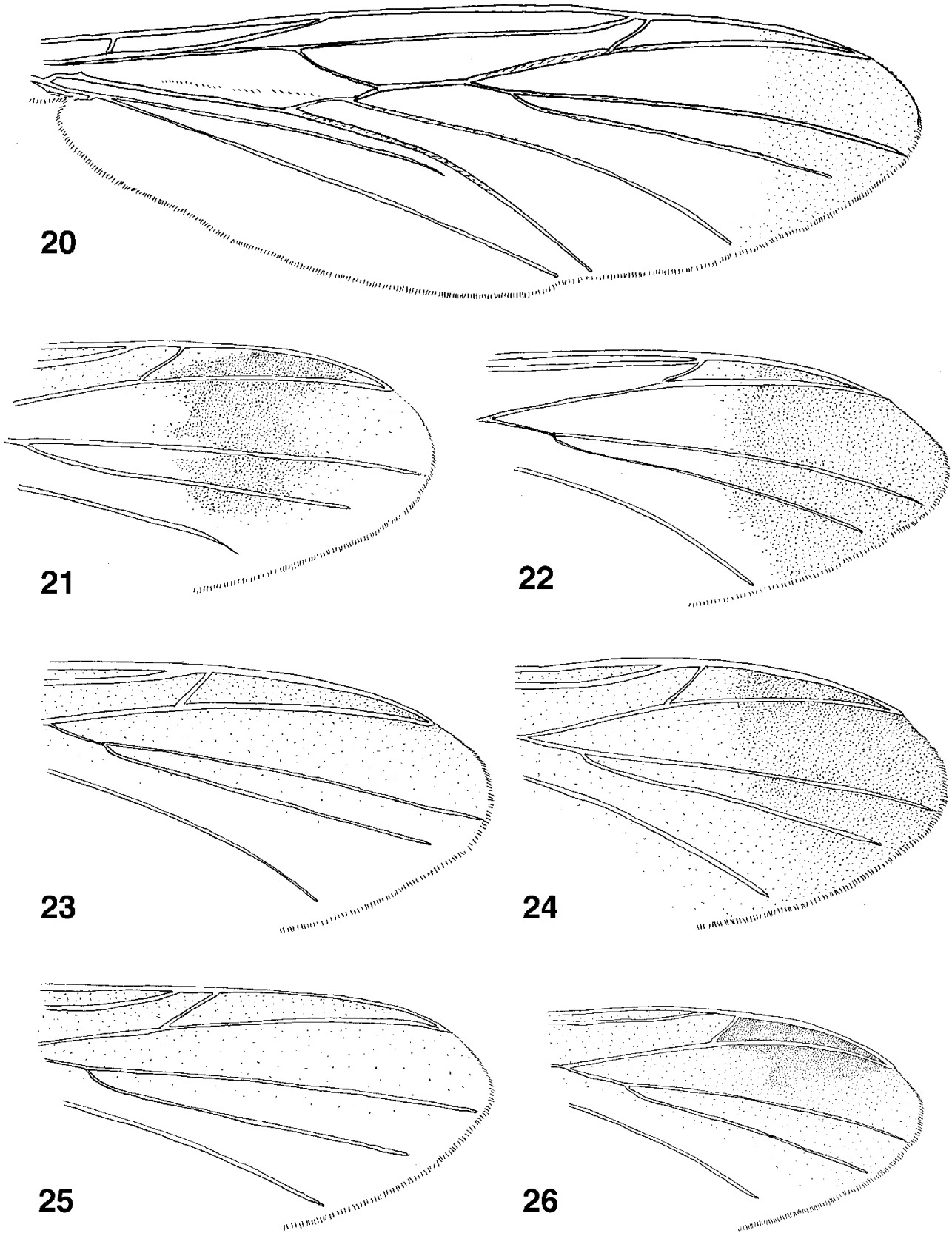

FIGURES 20-26. Isoneuromyia wings, showing apical patterning. 20. I. splendida, n. sp. 21. I. subapicalis, n. sp. 22. I. nigribasis, n. sp. 23. I. glabra, n. sp. 24. I. nigerrima, n. sp. 25. I. jata, n. sp. 26. I. yorki, n. sp. 
Infuscation: Essentially two types of wing infuscation occur in the specimens examined: 1) a distinct area of infuscation subapically that may extend to the wing margin as a paler color or the same color (cf. Figs 20-22, 24, 26); and 2) no infuscation except at most yellowish to pale brownish tinting along the anterior costal margin as far as the tip of the wing (cf. Figs. 23, 25).

Abdomen

Shape of terminal segments: In some species, the terminal abdominal segments are flattened laterally and expanded, which may be a form of mimicry with a wasp. Models have not been found in this study; however, Edwards (1933) described I. polybioides as a mimic of the wasp Polybioides raphigastra (de Saussure), the specimen of which was placed in the same collection alongside the keroplatid by its collector because of the presumed mimicry.

\section{Male genitalia}

Gonostylus: Slight differences have been found among most of the species examined in this study, the most notable being coloration, levels of pilosity, and two Laotian species (brunettii, n. sp.; glabra, n. sp.) having the gonostylus multidentate (Figs. 35-36) instead of the typical bidentate condition. Two species (nigerrima, $\mathbf{n}$. sp.; variabilis, n. sp.) have a short peg-like tooth in close association with but separate from the lower of the two teeth in the otherwise bidentate condition.

\section{Female genitalia}

Cerci: Of the few female specimens examined in this study, some species have the cerci small and subhemispherical in shape (Fig. 10), while others have the cerci considerably elongated (Fig. 9), the latter of which may be an adaptation to specialized oviposition habits.
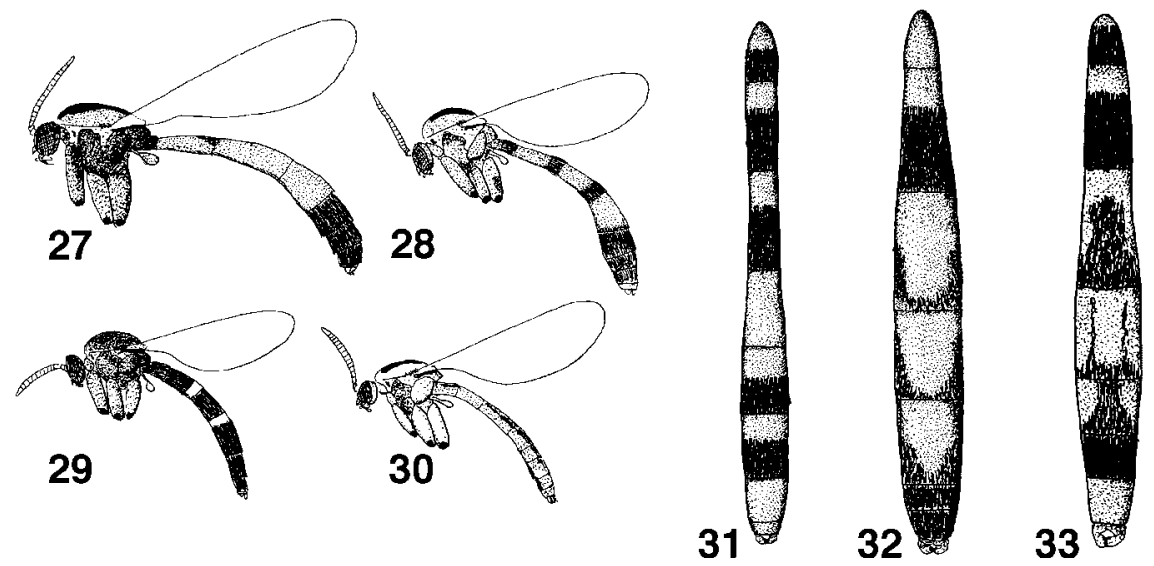

FIGURES 27-33. 27-30. Isoneuromyia habituses, lateral view showing thoracic and abdominal shapes and patterning, legs beyond coxae removed and wing venation not shown. 27. I. brunettii, $\mathbf{n}$. sp. 28. I. variabilis, n. sp. 29. I. nigerrima, n. sp. 30. I. pallidopsis, n. sp. 31-33. Isoneuromyia abdomens, dorsal view showing patterning. 31. I. splendida, n. sp. 32. I. subapicalis, n. sp. 33. I. nigribasis, $\mathbf{n}$. sp. 
1. Tibial spurs yellow to orange.

- Tibial spurs brownish black to black ....................................................................... 5

2. Wing with infuscation apically; basal flagellomeres orange, apical ones black (Fig. 5)... (Borneo) polybioides (Edwards)

- Wing completely hyaline; flagellomeres unicolorous

3. Frons, face, and fore coxae yellow ... (Sulawesi) 3

- Frons and face brown ... (Borneo).... .pallidopsis Evenhuis, n. sp.

4. Scutellum predominantly yellow matilei Evenhuis, n. sp.

- Scutellum dark brown tannia Evenhuis, n. sp.

5. Wing completely hyaline or with yellowish tinting along anterior margin. 6

- Wing smoky apically or with distinct infuscation apically or subapically..... 10

6. Mesonotum orange, without contrasting dark pattern, or with weak brown stripes, median stripe faded or absent.

- Mesonotum all black or yellowish with contrasting black to brown pattern; fore tibia with distinctive shiny orange pecten comb apically.

7. Mesonotum with brown hairs posteriorly (Fig. 18); gonostylus (cf. Fig. 34) bidentate ... (Borneo) xanthina (Edwards)

- Mesonotum with golden yellow tomentum, black hairs restricted to patches above wing root (Fig. 12); gonostylus (Fig. 36) multidentate ... (Laos)

glabra Evenhuis, n. sp.

8. Forecoxagoldenyellowtomentose, withoutdarkhairsexcepttypicalapicalones...(Borneo)

Fore coxa with black hairs throughout flava Evenhuis, n. sp.

9. Scutellumyellow;palpibrown;forefemurwithdensehairsbasally,bareapically...(Borneo) jata Evenhuis, n. sp.

- Scutellum brown; palpi yellow; fore femur with black hairs evenly distributed ... (Laos) variabilis Evenhuis, n. sp.

10. Occiput predominantly orange to yellow with darker occipital triangle. 11

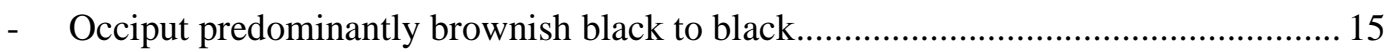

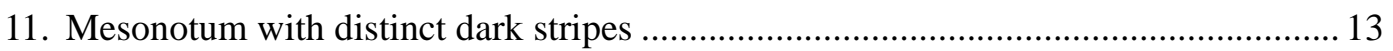

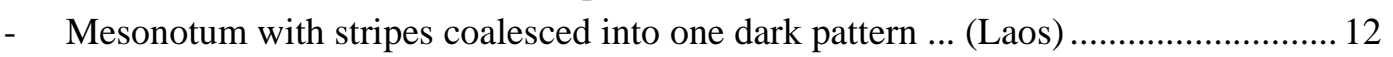

12 Basalantennalflagellomeresbrown,apicalsegmentsyellow; gonostylus(Fig.34)bidentate splendida Evenhuis, n. sp.

- Antennal flagellomeres all yellowish orange; gonostylus (Fig. 35) multidentate brunettii Evenhuis, n. sp.

13. Antennal flagellomeres unicolorous 14

- Basal antennal flagellomeres black, apical ones yellow to orange ... (Laos)

14. Wing with apical infuscation extending to wing margin ... (Taiwan) nigribasis Evenhuis, n. sp. 
- Wing with spot of infuscation subapically, not extending to wing margin ... (Laos) ..... subapicalis Evenhuis, n. sp.

15. Abdomen predominantly yellow orange to reddish orange

- Abdomen predominantly black

16. Antennal flagellomeres black. rufescens (Brunetti)

- Antennal flagellomeres reddish yellow

17. Palpi brown; fore coxa brown basally, yellow apically ... (India)..... grandis (Brunetti)

- Palpi yellow; fore coxa all yellow to orange ... (Vietnam) yorki Evenhuis, n. sp.

18. Antennal flagellomeres reddish yellow ... (Bangladesh, India, Sri Lanka)

annandalei Brunetti

- Antennal flagellomeres brown to black 19

19. Abdominal segment 5 with yellow basally ... (Java) elegantissima (Tollet)

- Abdominal segment 5 all black 20

20. Face yellow; ocellar triangle darker than immediate surrounding area; fore femur brown dorsally, yellow ventrally ... (Java) pulcherrima (Tollet)

- Face brown; ocellar triangle and immediate surrounding area black; fore femur entirely reddish yellow with dense black hairs ... (Laos)..... nigerrima Evenhuis, n. sp.

\section{Descriptions of new species}

\section{Isoneuromyia nigribasis Evenhuis, $\mathbf{n} . \mathbf{s p}$.}

(Figs. 15, 22, 33, 38)

\section{Diagnosis}

Similar to splendida in both having the basal antennal flagellomeres brown and the apical ones yellow to orange. It can be easily distinguished from splendida by the distinct and separate mesonotal stripes (coalesced in splendida) and the normally shaped lower tooth at the apex of the gonostylus (this tooth shaped like a shark's tooth in splendida).

\section{Description}

MALE. Lengths: Body: $12.2 \mathrm{~mm}$; wing; $8.3 \mathrm{~mm}$.

Head. Vertex and occiput immediately behind ocelli black; remainder of occiput orange with fairly dense small black recumbent hairs. Ocelli in horizontal line. Frons dark brown, bare. Antennae: scape and pedicel cup-shaped, brown. Flagellum: segments slightly compressed; flagellomeres 1-6 brown; flagellomere 7 reddish brown; flagellomeres 8-14 yellowish. Face brown, silvery pruinose with small black hairs apicolaterally. Palpi reddish brown. Proboscis dark brown.

Thorax. Mesonotum brownish yellow with three black stripes (Fig. 15), medial stripe extending anteriorly to pronotum. Scutellum dark brown. Mesonotum with uniformly 
distributed small recumbent black hairs dorsally, patch of thick black setae above wing root and on posterior margin of scutellum. Prescutellar area tapering to scutellum. Pronotal lobes dark brown with dense black setae. Pleura and mediotergite dark brown, bare. Halter orange.

Legs. Coxae reddish brown with black hairs; fore and hind coxa with spot of black basally. Fore and mid femora reddish brown, hind femur black, all with recumbent black hairs. Fore tibia with small black tibial pecten apically. Tibial spurs black. Fore basitarsus $1.3 \mathrm{x}$ length of fore tibia. Mid and hind basitarsi subequal in length to lengths of respective tibiae. Claws minute.

Wing (Fig. 22). Grayish yellow hyaline anteriorly along costal margin, becoming more clear posteriorly; with brown infuscation apically from costa to apex of cell $\mathrm{m} 2$; apex of cell cua1 with small cloud of brown apically; vein $\mathrm{R}_{4}$ slightly sinuous, ending in $\mathrm{C}$ slightly beyond end of $\mathrm{R}_{1}$.

Abdomen. Tergites I-III black with yellow basally, dense black recumbent hairs on black portion of segments, bare on yellow portion; tergite IV reddish yellow with pair of sublateral brown longitudinal stripes; tergites V-VII predominantly yellowish orange with scattered black tomentum laterally, dense dorsally; tergite VIII yellow with yellow hairs. Sternum patterned as on tergites except I-III with brown color medially.

Hypopygium. Not dissected. Gonocoxites grayish brown. Gonostyli yellowish brown, densely fine yellow pilose, apex with two dark black dentae.

FEMALE. Unknown.

Types

Holotype ơ (BPBM 16,595) from: LAOS: Vientiane Province: Ban Van Eue, 30 Mar 1966, native collector. [The actual locality is Ban Van Heue, $20 \mathrm{~km}$ E of Phou-kow-kuei in Vientiane Province, Laos. However, all the labels have the locality spelled as "Ban Van E ue", which is kept here in order to allow retrieval of the specimens by future workers.]

\section{Etymology}

The species epithet derives from the Latin niger $=$ black + basis $=$ base, referring to the dark basal flagellomeres of the antennae.

Isoneuromyia splendida Evenhuis, n. sp.

(Figs. 1, 4, 7, 17, 20, 31, 34)

\section{Diagnosis}

Closest to brunettii but can be distinguished from it by the brown basal antennal flagellomeres (these basal segments yellowish orange in brunettii). 
MALE. Lengths: Body: 15.0-18.5 mm; wing; $8.0-10.0 \mathrm{~mm}$.

Head. Vertex and occiput immediately behind ocelli black; remainder of occiput orange with fairly dense small black recumbent hairs. Ocelli in horizontal line. Frons black, bare. Antennae: scape and pedicel black basally, brown apically. Flagellum: segments slightly compressed; flagellomeres 1-7 brown; flagellomeres 8-14 yellowish. Face orange, yellowish pruinose with small black hairs apicolaterally. Palpi dark brown. Proboscis orange.

Thorax. Mesonotum yellowish with three black stripes coalesced into one (Fig. 17), medial stripe extending anteriorly to pronotum. Scutellum dark brown. Mesonotum with uniformly distributed recumbent yellow hairs dorsally, patch of thick black setae above wing root and on posterior margin of scutellum. Prescutellar area tapering to scutellum. Pronotal lobes dark brown with dense black setae. Pleura and mediotergite dark brown, bare. Halter orange, knob orange with brown dorsally.

Legs. Fore and mid coxae orange, hind coxa brown, all with admixture of yellow tomentum and black hairs. Fore and mid femora reddish brown, hind femur black, all with recumbent black hairs. Fore tibia with orange tibial pecten apically. Tibial spurs black. Fore basitarsus $1.3 \mathrm{x}$ length of fore tibia. Mid and hind basitarsi subequal in length to lengths of respective tibiae. Claws minute.

Wing (Fig. 20). Grayish yellow hyaline anteriorly along costal margin, becoming more clear posteriorly; vein $R_{4}$ slightly sinuous, ending in $C$ slightly beyond end of $R_{1}$; veins $M_{2}$ and $\mathrm{CuA}_{1}$ not quite reaching wing margin; vein $\mathrm{A}_{1}$ complete.

Abdomen. Tergites I-III black with orange basally, dense black recumbent hairs on black portion of segments, bare on yellow portion; tergites IV-VII predominantly yellowish orange; tergites IV, VII-VIII with yellow hairs; tergites V-VI with black tomentum, densest apically. Sternum patterned as on tergites.

Hypopygium (Fig. 34). Gonocoxites and gonostyli yellowish brown, densely fine yellow pilose, apex bidentate, basal tooth shaped like a shark's tooth; two minute dark sclerotized teeth in between large darkly sclerotized teeth (Fig. 34B).

FEMALE. Unknown.

Types

Holotype ${ }^{\rtimes}$ (BPBM 16,597) from: LAOS: Vientiane Province: Ban Van Eue, 29 Mar 1966, native collector. Paratypes: LAOS: Vientiane Province: 10 ${ }^{\star}$, Ban Van Eue, 15-31 May 1965, native collector; $10^{\star}$, same data, 15 May 1966; 1?[abdomen missing], same data, 31 May 1966; 20 same data, 30 June 1966. Holotype in BPBM. Paratypes in BPBM and MNHN.

Etymology

The species epithet derives from the Latin splendidus = bright, shining, referring to the striking contrasting color pattern of the thorax, legs, and antennae. 


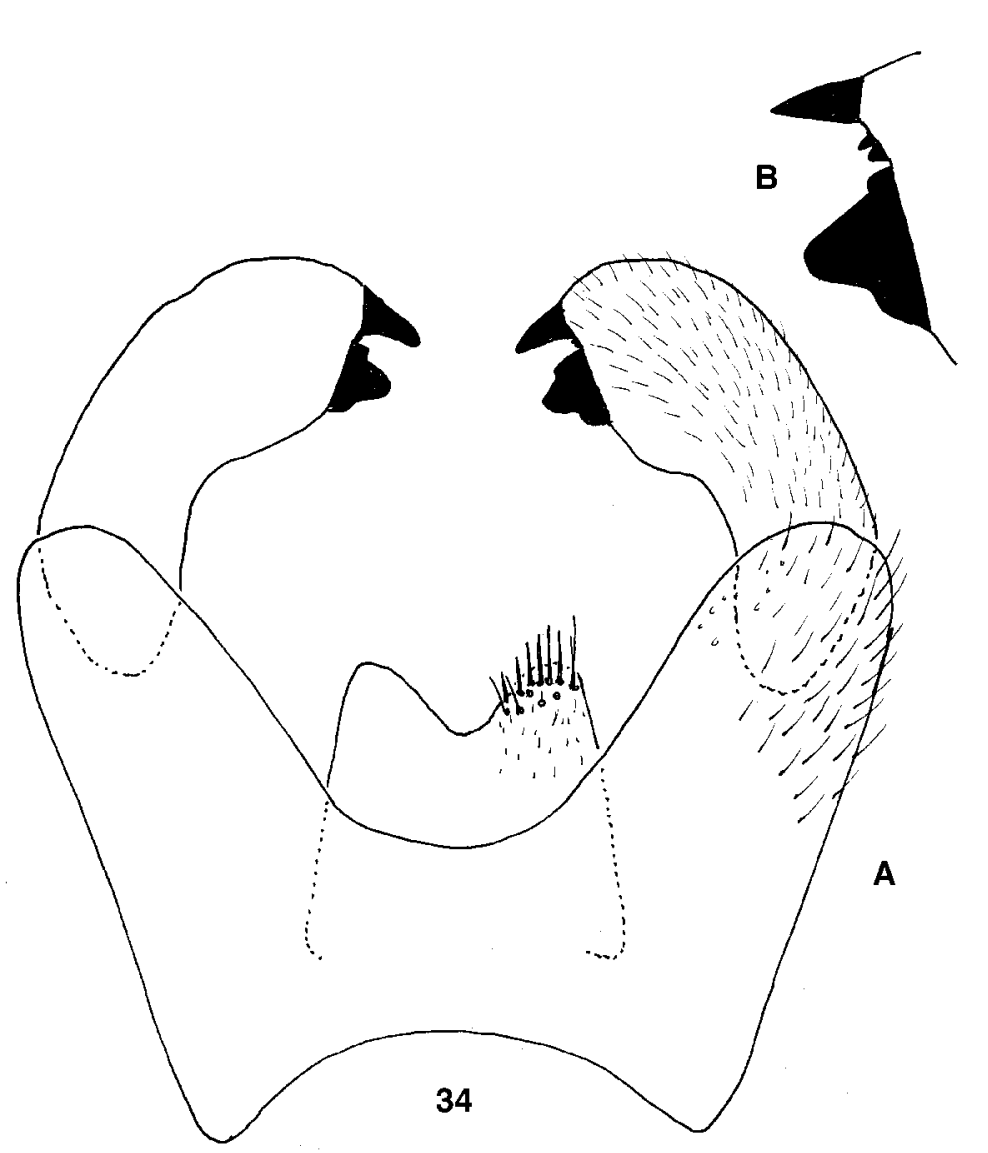

FIGURE 34. Isoneuromyia splendida, n. sp. A. Male genitalia, dorsal view. B. Detail of apex of gonostylus, showing minute teeth in between larger teeth.

\section{Isoneuromyia subapicalis Evenhuis, $\mathbf{n}$. sp.}

(Figs. 21, 32, 40)

\section{Diagnosis}

Closest in appearance to formosana but can be easily distinguished by the subapical spot of infuscation on the wing (this infuscation extends to the wing apex in formosana).

\section{Description}

MALE. Lengths: Body: 10.5-13.5 mm; wing; 7.6-8.5 mm.

Head. Vertex and occiput immediately behind ocelli black; remainder of occiput yellowish orange with fairly dense small black recumbent hairs. Ocelli in horizontal line. Frons yellowish brown, bare. Antennae yellowish orange; scape and pedicel silvery pruinose. Face yellow, silvery pruinose with a few black hairs apically. Palpi orange, last palpomere with brown dorsally. Proboscis yellowish orange. 
Thorax. Mesonotum predominantly yellowish with three black stripes, medial stripe extending anteriorly to pronotum. Scutellum yellow with black hairs. Mesonotum with admixture of scattered small recumbent black hairs and yellow tomentum dorsally, patch of thick black setae above wing root and on posterior margin of scutellum. Prescutellar area tapering to scutellum. Pronotal lobes yellow with black setae laterally. Pleura and mediotergite yellow, bare. Halter yellowish white.

Legs. Coxae yellow to orange with black hairs. Femora yellow with recumbent black hairs, dense pilose areas appearing brown. Fore tibia with orange tibial pecten apically. Tibial spurs black. Basitarsi subequal in length to lengths of respective tibiae. Claws minute.

Wing (Fig. 21). Yellowish hyaline anteriorly along costal margin, become more clear posteriorly; with brown infuscation subapically from costa to apex of cell $\mathrm{m} 2$, clear at apex of wing, cloud of brown surrounding venation at $\mathrm{r}-\mathrm{m}$ fusion; vein $\mathrm{R}_{4}$ slightly sinuous, ending in $\mathrm{C}$ slightly beyond end of $\mathrm{R}_{1}$; veins $\mathrm{M}_{1}, \mathrm{M}_{2}, \mathrm{CuA}_{1}$, and $\mathrm{A}_{1}$ not quite reaching wing margin.

Abdomen. Tergites I-IV yellow, brown apically, dense black recumbent hairs on brown portion of segments making them appear black, bare on yellow portion; tergites V-VII predominantly brown with scattered black tomentum, dense dorsally; tergite VIII yellowish brown. Sternum patterned as on tergites.

Hypopygium (Fig. 40). Gonocoxites and gonostyli yellowish brown, densely fine yellow pilose, gonostylar apex with two long sclerotized black teeth, somewhat recurved downward, cleft between teeth deep.

FEMALE. As in male, but terminal segments of abdomen (V-VII) expanded; cerci yellowish brown, small, only slightly exserted.

Types

Holotype $\sigma^{x}$ (BPBM 16,598) and paratype $\sigma^{x}$ from: LAOS: Vientiane Province: Ban Van Eue, 30 Jun 1967, native collector. Other paratypes: LAOS: $10^{\star}$, same data, 30 Nov 1965; 1 우, same data, 30 Aug 1967; 2๙, 1? [abdomen missing], same data, 15 Sep 1967;

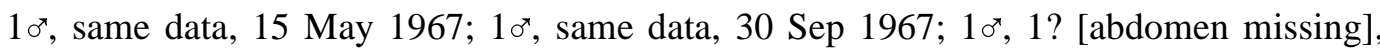

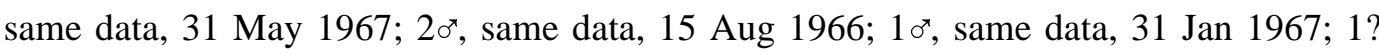
[abdomen missing], same data, 31 Jul 1965; Sayaboury Province: Sayaboury, $10^{\star}$, 30 Sep 1966, native collector. Holotype in BPBM. Paratypes in BPBM and MNHN.

Etymology

The species epithet refers to the characteristic subapical infuscation on the wing. 


\section{Diagnosis}

Closest to splendida but can be distinguished from it by the all yellow-orange flagellomeres (brown basally in splendida) and the multidentate gonostylus (bidentate in splendida).

Description

MALE. Lengths: Body: 12.0-16.0 mm; wing; 7.5-11.0 mm.

Head. Vertex and occiput immediately behind ocelli black; remainder of occiput brown to orange with fairly dense small recumbent hairs. Ocelli in horizontal line. Frons orange, bare. Antennae (cf. Fig. 6) orange. Face orange, dense silvery pruinose with a few yellow hairs laterally. Palpi and proboscis orange.

Thorax. Mesonotum orange with three black stripes coalesced into one (Fig. 11), medial stripe extending anteriorly to pronotum. Scutellum black with thin orange posterior margin. Mesonotum with scattered yellow recumbent hairs dorsally, patch of thick black setae above wing root, on postalar calli, and a few small black hairs on posterior margin of scutellum. Prescutellar area tapering to scutellum. Pronotal lobes brown with scattered fine black hairs. Pleura and mediotergite dark brown, bare. Halter orange.

Legs. Coxae brown basally, yellow apically, with admixture of yellow tomentum and scattered black hairs. Fore and mid femora yellow, hind femur brown, all predominantly bare with recumbent black hairs only on dorsal surface. Fore tibia with small brownish tibial pecten. Tibial spurs black. Fore basitarsus $1.2 \mathrm{x}$ length of fore tibia. Mid and hind basitarsi subequal in length to lengths of respective tibiae. Claws minute.

Wing. Subhyaline; vein $R_{4}$ straight, ending in $C$ slightly beyond end of $R_{1}$; vein $A_{1}$ complete, reaching wing margin.

Abdomen. Tergite I black with dense recumbent black hairs; tergites II-IV orange with scattered golden tomentum; tergites V-VII black with recumbent black hairs; tergite VIII orange with yellow hairs. Sternum patterned as on tergites.

Hypopygium (Fig. 35). Not dissected. Gonocoxites and gonostyli orange, yellow pilose, apex of gonostyli multidentate, largest teeth apically, row of smaller teeth basally.

FEMALE. Same as male except: pronotal lobes yellow with a spot of brown; fore coxae yellow, mid and hind coxae brown; cerci (Fig. 9) long, as long as abdominal segment $\mathrm{V}$ with scattered fine brown hairs.

Types

Holotype $\left.\sigma^{\rtimes(B P B M} 16,589\right)$ from: LAOS: Vientiane Province: Ban Van Eue, 15 May 1966, native collector. Paratype: LAOS: Vientiane Province: 1ㅇ, same data, 30 Mar 1966. Holotype and paratype in BPBM. 
The species name honors the author of the genus Isoneuromyia, Enrico Adelemo Brunetti (1862-1927).

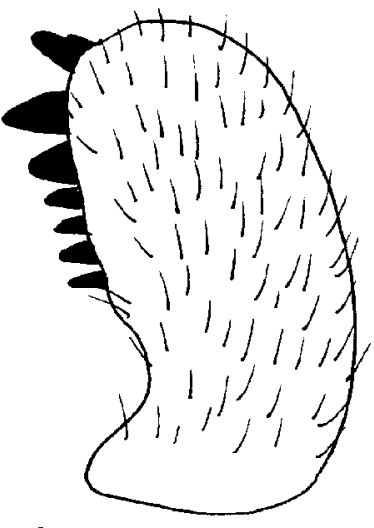

35

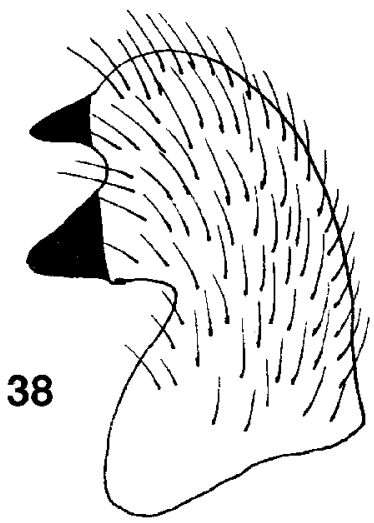

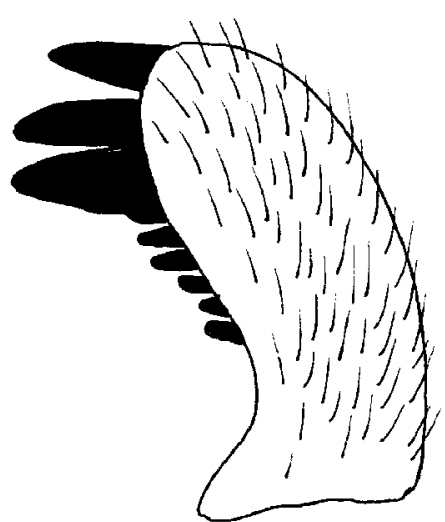

36

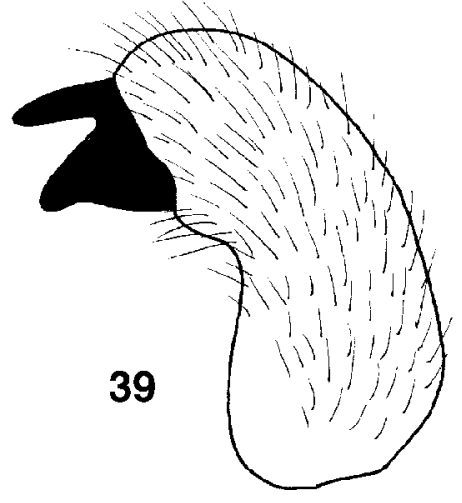

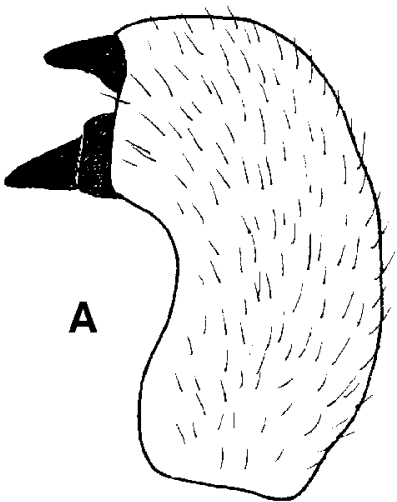

37

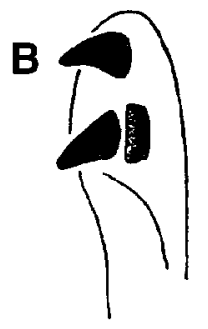

FIGURES 35-39. Isoneuromyia gonostyli. 35. I. brunettii, n. sp. 36. I. glabra, n. sp. 37. I. nigerrima, n. sp. A. Gonostylus. B. Detail of apex showing peg-like tooth. 38. I. nigribasis, n. sp. 39. I. pallidopsis, n. sp.

\section{Isoneuromyia pallidopsis Evenhuis, n. sp.}

(Figs. 16, 30, 39)

\section{Diagnosis}

This species fits in the group of species possessing yellow to orange tibial spurs. It appears closest to polybioides but can be separated from it by the all yellow flagellomeres (black apically in polybioides) and the all hyaline to subhyaline wing (with apical infuscation in polybioides). 
MALE. Lengths: Body: $6.0-9.0 \mathrm{~mm}$; wing; $7.0-7.5 \mathrm{~mm}$.

Head. Vertex and occiput immediately behind ocelli black; remainder of occiput orange with scattered yellow tomentum, black hairs in a row along posterior eye margin. Ocelli in horizontal line. Frons yellow, bare. Antennae yellowish. Face brown, silvery pruinose with small black hairs apicolaterally. Palpi and proboscis orange-yellow.

Thorax. Mesonotum and scutellum yellow with three black mesonotal stripes coalesced into one (Fig. 16), medial stripe extending anteriorly to pronotum. Mesonotum with uniformly distributed small recumbent yellow hairs dorsally, patch of thick black setae above wing root and on posterior margin of scutellum. Prescutellar area flared laterally at postalar calli. Pronotal lobes yellow, a few black setae laterally. Laterotergite and mediotergite yellow, remainder of pleura brown, pleura bare. Halter yellow with orange knob.

Legs. Fore coxa yellow, mid and hind coxae orange, all dense yellow tomentose apically; Femora yellow with yellow tomentum. Fore tibia with orange tibial pecten apically. Tibial spurs yellowish orange. Fore basitarsus $1.2 \mathrm{x}$ length of fore tibia. Mid and hind basitarsi subequal in length to lengths of respective tibiae. Claws minute.

Wing. Grayish yellow hyaline anteriorly along costal margin, clear elsewhere; vein $\mathrm{R}_{4}$ slightly sinuous, ending in $\mathrm{C}$ slightly beyond end of $\mathrm{R}_{1}$; veins $\mathrm{M}_{2}, \mathrm{CuA}_{1}, \mathrm{CuA}_{2}$, and $\mathrm{A}_{1}$ not quite reaching wing margin.

Abdomen. Tergites (Fig. 30) reddish brown with black mottling dorsolaterally; tergite I with recumbent black hairs posterodorsally. Sternum patterned as on tergites.

Hypopygium (Fig. 39). Gonocoxites and gonostyli dark brown, with black hairs, apex with two dark large black teeth fused together at their base.

FEMALE. Unknown.

Types

Holotype $\sigma^{\pi}(\mathrm{BPBM} 16,596)$ and paratype ${ }^{*}$ from: INDONESIA: Sulawesi: $100 \mathrm{~km}$ N. Palopo, Lamasie, 23 Ju-n10 Jul 1966, R. Straatman. Holotype and paratype in BPBM.

Etymology

The species epithet derives from the Latin pallidus $=$ pale + opsis $=$ appearance , referring to the characteristic pale coloration.

\section{Isoneuromyia nigerrima Evenhuis, $\mathbf{n}$. sp.}

(Figs. 3, 24, 29, 37)

Diagnosis

Closest to pulcherrima but can be distinguished from it by the brown face (yellow in 
pulcherrima), the fore femur being entirely reddish yellow (fore femur brown dorsally, yellow ventrally in pulcherrima), and the ocellar callus concolorous with the surrounding frontal and occipital areas (the callus contrasting in color with the surrounding area in pulcherrima).

\section{Description}

MALE. Lengths: Body: 8.0-9.0 mm; wing; 5.8-6.0 mm.

Head. Vertex and occiput immediately behind ocelli black, brown near occipital foramen, remainder of occiput orange with fairly dense small recumbent black hairs above, yellow tomentose below. Ocelli in horizontal line. Frons with upper portion black, lower portion yellowish orange, bare. Antennae brown, scape and pedicel with tinge of yellow apically. Face orange, silvery pruinose with a few hairs laterally. Palpi reddish brown, last palpomere brown. Proboscis orange.

Thorax. Mesonotum predominantly dark brown with silvery pruinosity, anteromedial portion of mesonotum lighter brown. Scutellum dark brown. Mesonotum with uniformly distributed small recumbent black hairs dorsally, patch of thick black setae on postalar calli and posterior margin of scutellum. Prescutellar area tapering to scutellum. Pronotal lobes dark brown with black setae laterally. Pleura and mediotergite dark brown, bare. Halter yellow.

Legs. Coxae yellowish, black basally, with black hairs. Fore and mid femora brown basally, yellow apically, hind femur dark brown, all femora with recumbent black hairs. Fore tibia with orange tibial pecten apically. Tibial spurs black. Fore basitarsus $1.2 \mathrm{x}$ length of fore tibia. Mid and hind basitarsi subequal in length to lengths of respective tibiae. Claws minute.

Wing (Fig. 24). Subhyaline with brown infuscation subapically from costa to apex of cell $\mathrm{m} 2$; vein $R_{4}$ slightly sinuous, ending in $C$ slightly beyond end of $R_{1}$; veins $M_{2}, C u A_{1}$, and $\mathrm{A}_{1}$ not reaching wing margin.

Abdomen. Tergites I-II and V-VI black, with dense recumbent black hairs; tergites III-IV yellow basally, bare; tergites VII-VIII yellowish with yellow hairs. Sternum as on tergites.

Hypopygium (Fig. 37). Gonocoxites and gonostyli yellowish, with fine black hairs, apex with two large dark black teeth and one squarish peg-like tooth (Fig. 37B) in close association with lower black tooth (gonostylus needs to be turned slightly to see it).

FEMALE. Unknown.

Types

Holotype $\sigma^{x}$ (BPBM 16,594) and paratype $\sigma^{x}$ [tip of abdomen missing] from: LAOS: Vientiane Province: Ban Van Eue, 30 Jun 1967, native collector. Holotype and paratype in BPBM. 
Etymology

The species epithet derives from the Latin niger = black, referring to the predominantly black coloration of the thorax and abdomen.

\section{Isoneuromyia matilei Evenhuis, n. sp.}

(Fig. 14)

\section{Diagnosis}

Closest to tannia but can be distinguished from it by the yellow scutellum (scutellum brown in tannia).

\section{Description}

MALE. Lengths: Body: $7.8 \mathrm{~mm}$; wing; $6.0 \mathrm{~mm}$.

Head. Vertex and occiput black; with admixture of small recumbent black hairs and pale tomentum. Ocelli in horizontal line. Frons dark brown medially, yellowish brown laterally, bare. Antennae dark brown. Face dark brown, with a few brown hairs laterally. Palpi and proboscis dark orange.

Thorax. Mesonotum brownish yellow with three black stripes (Fig. 14), medial stripe extending anteriorly to pronotum. Scutellum yellow, brown basomedially as extension of medial mesonotal stripe. Mesonotum with uniformly distributed recumbent yellow tomentum dorsally, patch of thick black setae above wing root, on postalar calli, and on posterior margin of scutellum. Prescutellar area flared at postalar calli. Pronotum yellow medially, pronotal lobes dark brown with dense black setae. Pleura (except yellow laterotergite) and mediotergite dark brown, bare. Halter yellowish orange.

Legs. Coxae yellow with spot of brown basally, yellow tomentose, with black hairs apically. Femora brown basally, yellow apically, hind femur dark brown, all femora with yellow tomentum and hairs. Fore tibia with reddish brown tibial pecten apically. Tibial spurs yellow. Basitarsi slightly longer than respective tibiae. Claws minute.

Wing. Subhyaline anteriorly along costal margin, becoming more clear posteriorly; vein $R_{4}$ straight, ending in $C$ slightly beyond end of $R_{1}$; veins $M_{2}, C_{1} A_{1}$, and $A_{1}$ not reaching wing margin.

Abdomen. Tergites I-II yellow basally, brown apicomedially, dense recumbent black hairs on posterior portion of segments, bare basally; tergites III-VII orange with scattered black tomentum on tergite III, otherwise scattered yellow tomentose; tergite VIII brown, densely yellow pilose. Sternum patterned as on tergites.

Hypopygium. Not dissected. Gonocoxites and gonostyli grayish brown, densely fine yellowish brown pilose, apex with two dark black teeth.

FEMALE. Unknown. 
1140 Holotype $\sigma^{x}$ (BPBM 16,593) from: MALAYSIA [Borneo]: Sabah: Forest Camp, 19 km N. Kalabakan, 60 m, 17 Nov 1962, K.J. Kuncheria.

\section{Etymology}

This species is named in memory of Loïc Matile (1938-2000), for his valuable contributions to our knowledge of the systematics and phylogeny of the Keroplatidae.

\section{Isoneuromyia variabilis Evenhuis, $\mathbf{n}$. sp.}

(Figs. 8, 28, 42)

\section{Diagnosis}

Similar in appearance to jata but distinguished from it by the brown scutellum (yellow in jata) and the presence of hairs on the apex of the fore femur (this area bare in jata).

\section{Description}

MALE. Lengths: Body: 11.3-16.5 mm; wing; 7.0-9.2 mm.

Head. Vertex and occiput immediately behind ocelli black; remainder of occiput orange with yellow tomentum. Ocelli in horizontal line. Frons yellowish orange, bare. Antennae orange. Face yellow with brown mottling laterally, silvery pruinose. Palpi and proboscis orange.

Thorax. Mesonotum predominantly yellow with two to three black stripes, medial stripe extending anteriorly to pronotum but faded, reduced and not reaching pronotum, or absent altogether. Scutellum dark brown. Mesonotum with admixture of small recumbent black hairs and yellow tomentum, patch of thick black setae above wing root, on postalar calli, and posterior margin of scutellum. Prescutellar area tapering to scutellum. Pronotal lobes yellow with black hairs laterally. Pleura (except predominantly yellow laterotergite) and mediotergite dark brown, bare. Halter yellow.

Legs. Coxae yellow with black hairs; fore and hind coxae with spot of dark brown (amount of dark brown varies among specimens). Fore and mid femora yellow, hind femur yellowish with brown dorsoapically, all femora with recumbent black hairs, denser patches of black hairs appearing as brown ground color. Fore tibia with orange tibial pecten apically (Fig. 8). Tibial spurs black. Fore basitarsus $1.2 \mathrm{x}$ length of fore tibia. Mid and hind basitarsi subequal in length to lengths of respective tibiae. Claws minute.

Wing. Brownish yellow hyaline anteriorly along costal margin, subhyaline elsewhere; vein $R_{4}$ slightly sinuous, ending in $C$ slightly beyond end of $R_{1}$; veins $M_{2}, C u A_{1}$, and $C u A_{2}$ not reaching wing margin.

Abdomen. Thin, tergites IV-VI expanded in lateral view (Fig. 28). Tergites I-III, V black with orange basally, dense recumbent black hairs on black portion of segments, bare 
on orange portion; tergite IV orange with thin band of black color covered by black tomentum along posterior margin; tergites VI-VII black with dense black recumbent setae; tergite VIII yellow with yellow recumbent hairs. Sternum patterned as on tergites except I-IV with thin black band of recumbent hairs along posterior margin.

Hypopygium (Fig. 42). Gonocoxites and gonostyli reddish orange, densely fine yellowish white pilose, apex with two large dark black teeth and single short squarish peglike tooth in close association with lower tooth (gonostylus needs to be turned slightly to see this peg-like tooth).

FEMALE. As in male except abdominal segments predominantly orange, black posterobasally; cerci enlarged (cf. Fig. 9), length subequal to length of abdominal segment VI, with scattered minute brown hairs.

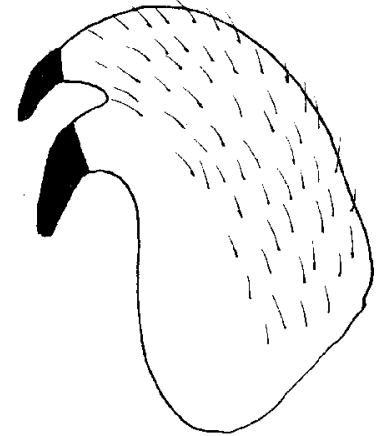

40

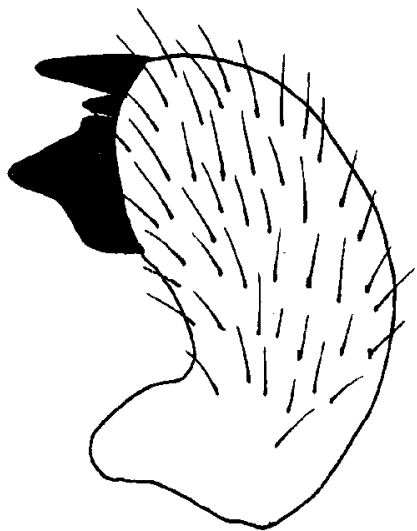

41
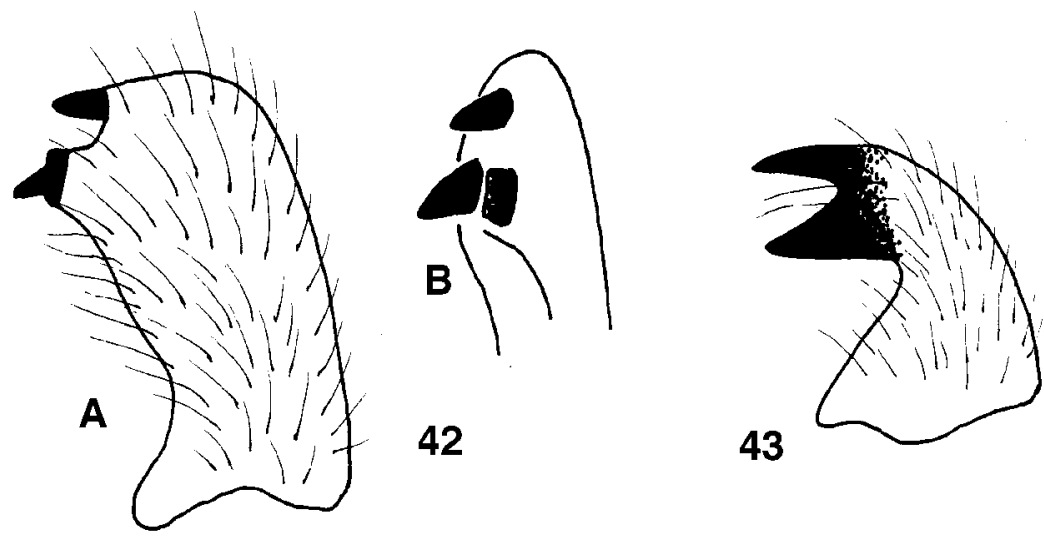

FIGURES 40-43. Isoneuromyia gonostyli. 40. I. subapicalis, n. sp. 41. I. tannia, n. sp. 42. $I$. variabilis, n. sp. A. Gonostylus. B. Detail of apex of gonostylus showing peg-like tooth. 43. I. yorki, n. sp.

Types

Holotype ơ (BPBM 16,600) and paratype + from: LAOS: Vientiane Province: Ban Van Eue, 15 May 1966, native collector. Other paratypes: LAOS: Vientiane Province: $1 \sigma^{\star}$, 


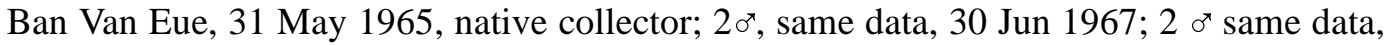
30 Sep 1966. Holotype in BPBM. Paratypes in BPBM and MNHN.

\section{Remarks}

In addition to the variability of the medial mesonotal stripe (see description above), the laterotergite varies from almost all yellow (with brown only ventrally) to (rarely) predominantly dark brown with paler medial area. In most specimens, the laterotergite is predominantly yellow or at least contrastingly paler than surrounding pleural sclerites. The tibial pecten also varies in size, but is always a shining orange in color.

\section{Etymology}

The species epithet derives from the Latin variabilis, referring to the variable nature of the medial mesonotal stripe, size of the tibial pecten, and coloration of the laterotergite.

\section{Isoneuromyia yorki Evenhuis, n. sp.}

(Figs. 2, 10, 19, 26, 43)

\section{Diagnosis}

Similar to the Indian species grandis but can be distinguished from it by the yellow palpi (brown in grandis) and the yellow fore coxa (brown basally in grandis).

\section{Description}

MALE. Lengths: Body: 5.0-6.5 mm; wing; 4.2-5.5 mm.

Head (Fig. 2). Vertex and occiput black, with small recumbent black hairs. Ocelli in horizontal line. Frons black, bare. Antennae brown. Face yellow with brown transverse band medially, silvery pruinose with small black hairs apically. Palpi yellow. Proboscis orange.

Thorax. Mesonotum (Fig. 19) dark brown. Scutellum reddish brown to pale brown. Mesonotum with yellow tomentum dorsally, small recumbent black hairs posteriorly, patch of thick black setae above wing root, on postalar calli, and on posterior margin of scutellum. Prescutellar area tapering to scutellum. Pronotal lobes dark brown with black setae laterally. Pleura and mediotergite dark brown, bare. Halter orange with dark brown along edge of knob.

Legs. Coxae yellowish orange with black hairs. Mid and hind coxae with spot of black color apically. Fore and mid femora yellow, hind femur black basally, all femora with fairly dense recumbent black hairs. Fore tibia with brownish orange tibial pecten apically. Tibial spurs black. Fore basitarsus $1.2 \times$ length of fore tibia. Mid and hind basitarsi subequal in length to lengths of respective tibiae. Claws minute.

Wing (Fig. 26). Subhyaline; with brown infuscation subapically from costa into apex 
of cell $\mathrm{r} 4$, fading posteriorly; vein $\mathrm{R}_{4}$ slightly curved upward, ending in $\mathrm{C}$ slightly beyond end of $\mathrm{R}_{1}$; veins $\mathrm{M}_{2}, \mathrm{CuA}_{1}, \mathrm{CuA}_{2}$, and $\mathrm{A}_{1}$ not reaching wing margin.

Abdomen. Tergites I-II black with dense recumbent black hairs; tergite III black with yellow color basally, predominantly black tomentose; tergites IV-VIII predominantly yellowish orange with black tomentum, tomentum becoming sparser on posterior segments.

Hypopygium (Fig. 43). Gonocoxites grayish brown. Gonostyli subtriangular in shape, dark brown, with stiff black setae, apex darkly sclerotized with two black teeth fused into a single bifid tooth.

FEMALE. As in male except for generally paler brown coloration of occiput, mesonotum and abdomen. The cerci (Fig. 10) are small and barely exserted from the terminal abdominal segments.

Types

Holotype $\sigma^{x}(16,601)$ and paratype + from: VIETNAM: $6 \mathrm{~km}$ S Dalat, $1400-1500 \mathrm{~m}$, 9 Ju-n7 Jul 1961, N.R. Spencer. Other paratypes: VIETNAM: 30, Fyan, 900-1000 m, 11 Jul-9 Aug 1961, N.R. Spencer. Holotype and paratypes in BPBM.

Etymology

The species epithet honors my good friend, Ken York, for service to his country in Vietnam in time of war.

\section{Isoneuromyia tannia Evenhuis, n. sp.}

(Fig. 41)

Diagnosis: Closest to matilei but can be easily separated from it by the brown scutellum (the scutellum yellow in matilei).

\section{Description}

MALE. Lengths: Body: 7.0-8.5 mm; wing; $5.0-5.5 \mathrm{~mm}$.

Head. Vertex and occiput immediately behind ocelli black; remainder of occiput black to brown with yellow tomentum, small erect black hairs restricted to posterior eye margin. Ocelli in horizontal line. Frons dark brown on upper portion, yellow on lower portion, bare. Antennae yellowish. Face yellow above, dark brown below, silvery pruinose with small black hairs apicolaterally. Palpi and proboscis yellow.

Thorax. Mesonotum black with yellowish brown humeral areas. Scutellum dark brown. Mesonotum with dense whitish tomentum dorsally, patch of thick black hairs above wing root, on postalar calli, and posterior margin of scutellum. Prescutellar area tapering to scutellum. Pronotal lobes dark brown with dense black setae laterally. Pleura 
(except yellow on medial portion of laterotergite) and mediotergite dark brown, bare. Halter orange-yellow.

Legs. Coxae reddish brown, with yellow tomentum, black hairs apically; fore coxa black on basal half, hind coxa black on extreme base. Femora brown, yellow apically, all yellow tomentose. Fore tibia with yellow tibial pecten apically. Tibial spurs black. Fore basitarsus $1.5 \mathrm{x}$ length of fore tibia. Mid and hind basitarsi subequal in length to lengths of respective tibiae. Claws minute.

Wing. Hyaline; vein $R_{4}$ straight, ending in $C$ slightly beyond end of $R_{1}$; veins $M_{2}$, $\mathrm{CuA}_{1}, \mathrm{CuA}_{2}$, and $\mathrm{A}_{1}$ not reaching wing margin.

Abdomen. Tergite I black, with dense recumbent black hairs; tergites II-III orange with black dorsomedially, with dense black and yellow tomentum; tergite IV-V black with black and yellow tomentum; tergites VI-VIII black with yellow tomentum. Sternum orange with yellow tomentum.

Hypopygium (Fig. 41). Gonocoxites and gonostyli brown, with stiff black and yellow hairs, apex with two dark large black teeth and single small black tooth in between them.

FEMALE. Unknown.

Types

Holotype $\sigma^{x}$ (BPBM 16,599) and paratype $\sigma^{x}$ from: MALAYSIA [Borneo]: Sabah: Forest Camp, 19 km N. Kalabakan, 60 m, 25 Oct 1962, K.J. Kuncheria.

\section{Etymology}

The species epithet derives from the Anglo-Saxon tannian = brown, referring to the characteristic brown color of the scutellum. It is treated here as adjectival.

\section{Isoneuromyia flava Evenhuis, n. sp.}

(Fig. 12)

\section{Diagnosis}

Similar in appearance to jata and variabilis but differs from them by having the fore coxa all yellow tomentose (fore coxa with black hairs throughout in jata and variabilis).

\section{Description}

MALE. Lengths: Body: $8.2 \mathrm{~mm}$; wing; $6.0 \mathrm{~mm}$.

Head. Vertex and occiput immediately behind ocelli black; remainder of occiput orange with fairly dense yellow tomentum. Ocelli in horizontal line. Frons brown, bare. Antennae brown. Face yellow above, dark brown below, silvery pruinose. Palpi and proboscis orange, last palpomere yellow with orange tip.

Thorax. Mesonotum yellow with three brown stripes (Fig. 12), medial stripe extending 
anteriorly to pronotum but faded. Scutellum yellow. Mesonotum with yellowish white

tomentum, patch of thick black setae above wing root, on postalar calli, and on posterior margin of scutellum. Prescutellar area tapering to scutellum. Pronotal lobes brown with stiff black setae laterally. Pleura (except yellow on posterior portion of katepisternum and all of laterotergite) and mediotergite dark brown, bare. Halter yellow with orange knob.

Legs. Coxae golden yellow with yellow tomentum, black hairs apically; fore coxa with spot of black basally. Femora brown basally, yellow apically, all with yellow tomentum. Fore tibia with orange tibial pecten apically. Tibial spurs brown. Fore basitarsus $1.2 \mathrm{x}$ length of fore tibia. Mid and hind basitarsi subequal in length to lengths of respective tibiae. Claws minute.

Wing. As in tannia, n. sp.

Abdomen. Tergites orange, dense recumbent black hairs on posterior margin of tergites I-II, yellow tomentose elsewhere, scattered black tomentum on tergites III-IV. Sternum all orange with yellow tomentum.

Hypopygium. Not dissected. Gonocoxites grayish brown. Gonostyli yellowish brown, densely fine yellow pilose, apex with two dark black dentae.

FEMALE. Unknown.

Types

Holotype $\sigma^{\rtimes}$ (BPBM 16,16,590) from: MALAYSIA [Borneo]: Sabah: Forest Camp, 19 km N. Kalabakan, 60 m, 4 Nov 1962, K.J. Kuncheria.

\section{Etymology}

The species epithet derives from the Latin flavus = golden yellow, yellow, referring to the generally yellow color of the body.

\section{Isoneuromyia jata Evenhuis, n. sp.}

(Fig. 25)

\section{Diagnosis}

Similar to variabilis but easily distinguished from it by the yellow scutellum (scutellum brown in variabilis) and the brown palpi (palpi yellow in variabilis).

\section{Description}

MALE. Lengths: Body: $7.0 \mathrm{~mm}$; wing; $5.7 \mathrm{~mm}$.

Head. Vertex and occiput immediately behind ocelli black; remainder of occiput yellow with fairly dense small black recumbent hairs, yellow tomentum on upper occiput. Ocelli in horizontal line. Frons yellowish white, bare. Antennae yellow; flagellomeres 1-6 with tinge of brown on dorsal surface. Face yellowish white, silvery pruinose with a few small black hairs apically. Palpi brown. Proboscis yellow. 
Thorax. Mesonotum yellow with three black stripes coalesced into one, medial stripe not reaching pronotum. Scutellum minute, yellow. Mesonotum with scattered yellow tomentum, patch of thick black setae above wing root, on postalar calli, and on posterior margin of scutellum. Prescutellar area flared at postalar calli, shield like, slightly covering base of scutellum. Pronotal lobes yellow with intermixed black and yellow tomentum. Pleura (except yellow laterotergite) dark brown, bare; mediotergite dark brown medially, yellowish laterally, bare. Halter yellowish white.

Legs. Coxae yellowish, with black hairs and tomentum, vestiture densest on fore coxa. Fore femur yellow; [mid legs beyond coxa missing]; hind femur yellow, black apically, all femora with recumbent black hairs on dark portions, yellow tomentum on yellow portions. Fore tibia with orange tibial pecten apically. Tibial spurs black. Fore basitarsus $1.2 \mathrm{x}$ length of fore tibia. Mid and hind basitarsi subequal in length to lengths of respective tibiae. Claws minute.

Wing (Fig. 25). Subhyaline anteriorly along costal margin, becoming more clear posteriorly; vein $R_{4}$ straight, ending in $C$ slightly beyond end of $R_{1}$; veins $M_{2}, C u A_{1}$, and $A_{1}$ not reaching wing margin.

Abdomen. Tergite I black, with dense recumbent black hairs; tergites II-IV orange basally, black apically, with yellow tomentum on orange portions, black tomentum on black portions; tergites V-VIII black, black tomentum laterally, dense dorsally. Sternum patterned as on tergites.

Hypopygium. Not dissected. Gonocoxites and gonostyli brown, densely stiff intermixed yellow and black pilose, apex with two dark black teeth.

FEMALE. Unknown.

Types

Holotype $\sigma^{\star}$ (BPBM 16,592) from: MALAYSIA [Borneo]: Sabah: Forest Camp, 19 km N. Kalabakan, 60 m, 12 Nov 1962, K.J. Kuncheria.

\section{Etymology}

This species is named for the sea-serpent goddess, Jata, worshiped by Borneo tribes as the co-creator of the Universe. It is treated here as a noun in apposition.

\section{Isoneuromyia glabra Evenhuis, n. sp.}

(Figs. 6, 12, 23, 36)

\section{Diagnosis}

Closest to xanthina from Borneo but can be easily distinguished by the golden yellow tomentum on the posterior of the mesonotum (this area with black recumbent hairs in xanthina) and the multidentate gonostylus (the apex of the gonostylus bidentate in xanthina). 
MALE. Lengths: Body: $11.3 \mathrm{~mm}$; wing; $7.8 \mathrm{~mm}$.

Head. Yellowish orange except small black ocellar triangle; occiput with sparse yellow tomentum. Ocelli in horizontal line. Antennae yellowish orange. Face silvery pruinose. Palpi and proboscis yellowish.

Thorax. Mesonotum and scutellum brownish yellow with two admedial brown stripes (Fig. 13), medial stripe absent. Mesonotum with scattered yellow tomentum, patch of thick black setae above wing root, on postalar calli, on and posterior margin of scutellum. Prescutellar area tapering to scutellum. Pronotal lobes yellow with black setae laterally. Pleura and mediotergite yellow, bare. Halter yellow.

Legs. [Mid legs missing]. Coxae yellow, yellow tomentose, with black hairs apically. Femora yellow, bare. Fore tibia with orange tibial pecten apically. Tibial spurs black. Fore basitarsus $1.2 \mathrm{x}$ length of fore tibia. Mid and hind basitarsi subequal in length to lengths of respective tibiae. Claws minute.

Wing (Fig. 23). Grayish yellow hyaline anteriorly along costal margin, becoming clear posteriorly; vein $R_{4}$ slightly sinuous, ending in $C$ slightly beyond end of $R_{1}$; veins $M_{2}$ and $\mathrm{CuA}_{1}$ not reaching wing margin.

Abdomen. Orange with dense yellow recumbent hairs; tergites VII-VIII with scattered black tomentum dorsally.

Hypopygium (Fig. 36). Not dissected. Gonocoxites and gonostyli orange-yellow, densely fine yellow pilose, apex multidentate.

FEMALE. Unknown

Types

Holotype o (BPBM 16,591) from: LAOS: Vientiane Province: Ban Van Eue, 15 May 1967 , native collector.

Etymology

The species epithet derives from the Latin glabrus $=$ bare, referring to the lack of brown hairs on the mesonotum and the bare femora.

\section{Notes on described species}

\section{Isoneuromyia polybioides (Edwards)}

Platyura (Isoneuromyia) polybioides Edwards, 1933: 226.

This species was originally described from a single male and female from Lumu Lumu [a locality at $5500 \mathrm{ft}$. on Mt. Kinabalu in Sabah in Borneo]. An additional male from Sabah has been examined in this study and shows only a slight difference in the amount of 
infuscation at the tip of the wing (fainter than in the types). The species was originally described as being unique in possessing orange tibial spurs. Specimens examined in this study show a complex of four species possessing orange to yellow spurs and restricted in range to Sulawesi and Borneo (the other three species being pallidopsis, n. sp., matilei, $\mathbf{n}$. sp., and tannia, n. sp.).

Material Examined: MALAYSIA: Sabah [Borneo]: 10 , Forest Camp, $19 \mathrm{~km} \mathrm{N.}$ Kalabakan, 60 m, 21 Nov 1962, K.J. Kuncheria (BPBM).

\section{Isoneuromyia formosana (Okada), n. stat.}

Zelmira annandalei f. formosana Okada, 1938: 36.

This species was originally described as a form of the Indian annandalei Brunetti. It is obviously a separate species based on characters given in the key above and its geographical distance from the range of annandalei both warrant raising it to specific status in this study.

\section{Isoneuromyia xanthina (Edwards)}

Platyura (Isoneuromyia) xanthina Edwards, 1931: 487.

This species was originally described from a single male and female in copula from Bettotan [= Bettotan River Camp near Sandakan in western Sabah in Borneo]. An additional male has been examined in this study.

Material Examined: MALAYSIA: Sabah [Borneo]: 1 $\varsigma^{\star}$, Forest Camp, $19 \mathrm{~km} \mathrm{N.}$ Kalabakan, 60 m, 14 Nov 1962, K.J. Kuncheria (BPBM).

\section{Neoplatyura ventosa (Sivec \& Plassmann), n. comb.}

Orfelia (Isoneuromyia) ventosa Sivec \& Plassmann, 1982: 7.

Sivec \& Plassmann (1982) described six new species of Mycetophilidae (s.l.) from Sri Lanka. One of these, Orfelia ventosa, was assigned by them to the subgenus Isoneuromyia but the authors noted the difference in the male genitalia, indicating that it was similar to that of Orfelia flava (Macquart) [now in Neoplatyura]. The illustration of the male genitalia provided by the authors is typical of Neoplatyura and I thus transfer the species to that genus. 
I thank the collectors of the material examined, specimens of which in Laos were collected by native villagers, allowing these new species to be discovered. I value the discussions on keroplatids I have had with Frank Howarth over the past few decades, which has helped fuel my interest in this family of flies. Two anonymous reviewers helped improve the manuscript.

\section{References}

Brunetti, E. (1912) Diptera Nematocera (excluding Chironomidae and Culicidae). In: Shipley, A.E. (ed.), The fauna of British India including Ceylon and Burma. [Diptera. Vol. I]. Taylor \& Francis, London, $\mathrm{xxx}+581 \mathrm{pp}$.

Chandler, P.J. \& Ribeiro, E. (1995) the Sciaroidea (Diptera) (excluding Sciaridae) of the Atlantic Islands (Canary Islands, Madeira and the Azores). Boletim do Museum Municipal do Funchal (História Natural) Suplemento, 3, 1-170.

Edwards, F.W. (1925) British fungus gnats (Diptera, Mycetophilidae). With a revised generic classification of the family. Transactions of the Entomological Society of London, 1924, 505-670.

Edwards, F.W. (1931) Diptera Nematocera from the lowlands of North Borneo. Journal of the Federated Malay States Museums, 16, 486-504.

Edwards, F.W. (1933) Diptera Nematocera from Mount Kinabalu. Journal of the Federated Malay States Museums, 17, 223-296.

Hutson, A.M., Ackland, D.M. \& Kidd, L.N. (1980) Mycetophilidae (Bolitophilinae, Ditomyiinae, Diadocidiinae, Keroplatinae, Sciophilinae, and Manotinae) Diptera, Nematocera. Handbooks for the Identification of British Insects, 9(3), 1-111.

Laffoon, J.L. (1965) Family Mycetophilidae (Fungivoridae). In: Stone, A., Sabrosky, C.W., Wirth, W.W., Foote, R.H. \& Coulson, J.R. (Eds.), A catalog of the Diptera of America north of Mexico. United States Department of Agriculture, Agricultural Handbook, 276, pp. 196-204.

Matile, L. (1990) Recherches sur la systématique et l'évolution des Keroplatidae (Diptera, Mycetophiloidea). Mémoires du Muséum National d' Histoire Naturelle (A), 148, 1-682.

Okada, I. (1938) Die von Herrn K. Takeuchi aus Japan gesammelten Nematoceren. Tenthredo, 2(1), $33-43$.

Sivec, I. \& Plassmann, E. (1982) Sechs neue Pilzmücken aus Sri Lanka (Diptera, Nematocera, Mycetophilidae). Spixiana, 5(1), 713.

Soli, G.E., Vockeroth, J.R. \& Matile, L. (2000) Families of Sciaroidea. In: Papp, L. \& Darvas, B. (E ds.), Contributions to a Manual of Palaearctic Diptera (with Special Reference to Flies of $E$ conomic Importance). Appendix. Science Herald, Budapest, pp. 49-92.

Vockeroth, J.R. (In Press). Keroplatidae. In: Brown, B.V. \& Zumbado, M. (Eds.), Manual of Central American Diptera. 